\title{
AC 2012-3230: CASE STUDY INCORPORATING SERVICE-LEARNING IN A STATICS AND DYNAMICS COURSE: THE WHEELCHAIR RAMP DESIGN/BUILD
}

\section{Dr. Jennifer Light, Lewis-Clark College}

Jennifer Light is an Associate Professor at Lewis-Clark State College where she teaches foundational engineering classes. She obtained her Ph.D. from Washington State University in interdisciplinary engineering and M.S. and B.S. degrees in environmental engineering from Idaho State University and Montana Tech, respectively. Light has extensive industry experience in the environmental engineering field with air and water quality. Research interests include improving the first-year experience, service learning, and retention in engineering, in addition to water and stormwater quality improvement. 


\title{
Case Study Incorporating Service-Learning in Statics and Dynamics Sequence Courses - The Wheelchair Ramp Design/Build
}

\begin{abstract}
This paper describes how one service-learning project was incorporated and improved through two sequenced courses, Engineering Statics and Dynamics, in a small school with limited resources and smaller classes.

The benefits of service-learning are well documented so including a service-learning component in engineering courses is a logical educational extension. However, developing meaningful and interesting service-learning projects for sophomore level engineering students that can be completed within a limited timeframe is challenging. This case study examines the development, implementation, improvement, and student experiences of an effective service-learning project for two sequenced, sophomore year, fundamental engineering courses.
\end{abstract}

Introduction

Providing engineering students with a genuine engineering service-learning experience that has a direct link to classroom content - specifically second year foundational engineering courses - is not easy. Finding projects that can be completed in a relatively short timeframe, are interesting and of value to students, and are within a student's technical ability, are things that make servicelearning projects difficult to find and develop. Despite these difficulties, engineering educators have incorporated service learning in their curriculums. Examples of service-learning in the freshmen and junior/senior years of an engineering program can be found with a search through the National Service-Learning Clearinghouse. ${ }^{1}$ However, there are few project-specific servicelearning opportunities for sophomore-level foundational engineering courses. This paper seeks to fill this gap by providing a description of a service-learning project developed specifically for a statics and dynamics class. It should be noted this case study is limited in scope in that the emphasis is on program evaluation rather than academic research. It is hoped, that through a description of the project genesis, chronological description of events, identified learning goals, and a description of the reflection and relationship to assessment and project improvement, this project could be replicated elsewhere.

Tsang $^{2}$ specifies four essential components for service-learning in engineering as: 1) identify a community need that matches course learning objectives and form a partnership; 2) create and implement a solution; 3) evaluate that solution for continuous improvement; and 4) engage students in structured reflection. The wheelchair ramp service-learning project described in this paper meets these four essential components as described below.

Statics and dynamics are the study of forces on objects. Students study forces in class, but do not always understand how the forces are developed or where they come from. Having an opportunity for students to identify and quantify forces are the first steps in design. Wheelchair 
ramps are a perennial need in our community and a local volunteer-based community agency coordinates volunteers to build these ramps. A partnership was developed with Interlink Volunteers (a local community agency providing support to community members wishing to live independently) to meet this need and match the course learning objectives of providing an engineering design experience specific to force analysis. Students identify the loading (forces) and then develop their wheelchair ramp design based on those loadings. Following that, they structurally analyze their design using concepts learned in the statics and dynamics courses and adjust their design based on their structural analysis and site/construction limitations.

The wheelchair ramp project allows the students to create and implement a solution. The project is narrow enough in scope that students can complete it within the course timeframe; the project is "hands-on" and student-centered; costs for the project are minimal since the community partner provides lumber; and the ramp can be built in a day. Also, wheelchair ramps at private residences don't require a building permit which allows more flexibility in determining where and when the ramp build can occur.

Along the way students are exposed to the realities of engineering - site limitations, tight deadlines, limited budgets, changing plans, and inclement weather. Students experience how the design and the final product do not always turn out as expected and how important it is to be able to make changes in the field that will not adversely affect the structural integrity. An opportunity to consider these issues is provided in a structured reflection. Students complete the reflection after the ramp is built and prior to the final exam in class. This structured reflection also serves as the mechanism for continuous project improvement

The paper is organized beginning with the project background section which describes the project creation and implementation chronologically. The changes and improvements section describes evaluation for continuous improvement, and the assessment section of the paper describes student reflections and how that information has been used to determine "effectiveness" of the service-learning project. In the conclusion section data is provided as a measure of evidence for service-learning that supports many of the benefits described in servicelearning literature. Although no claim is made to the causality between service-learning, increases in retention, and number of students entering the engineering program, circumstantial evidence provides support for continuing the service-learning projects at this institution.

\section{Project Background}

The wheelchair ramp project began in an engineering statics course as a means for a sophomore year culminating project. During the first semester statics class, the students designed a wheelchair ramp, and then analyzed static forces to determine the load limit for the ramp. This required finding properties (compression, modulus of rupture) of the wood they were using from the USDA wood manual ${ }^{3}$ and ensuring local building code was followed. ${ }^{4}$ Additionally, requirements from the American with Disabilities Act were researched with respect to how steep 
the ramp could be and railing placement. Finally, the students visited the site (this was not the actual site, but rather a "stand-in" as the actual build would take place later at a site to be determined), take measurements and note any limitations such as fences, water spigots, proximity of proposed ramp to the side of the house and windows.

At the end of the first class design phase the class along with the agency director and ramp coordinator review each group's design and discuss design advantages and drawbacks. The agency's ramp coordinator works with the students specifically about efficiency measures (adjusting width to accommodate standard plywood sheet sizes, lengths adjusted to minimize waste, etc.).

During the second semester class, dynamics, an actual building site for the wheelchair ramp is assigned. Student teams redesign their ramps based on the actual site then present their team designs with the class. The class and ramp coordinator together decide on a final design. After that, students begin the implementation part of the build.

Because the design and actual build are approximately five months apart, students use the "stand-in" site for practice designing and structurally analyzing the ramp during the first class. When the actual build site is assigned in the second class, students reconfigure their "stand-in" modular designs to accommodate the actual building site. This step turned out to be extremely valuable for both learning and time constraints. Student designs for the second, actual ramp were more detailed, realistic, and developed much quicker than the original designs. Students had five months between designs to think about their designs, analyze other ramps, and think about how ramps are constructed, and the improvement showed in their design reports.

One source of support that cannot be overlooked when undertaking a service-learning projectespecially in smaller schools-is the Service-learning Center if one is available. The ServiceLearning Center purchased t-shirts for participants and lunch on the day of the build in addition to providing publicity and signs. The support and, in particular, the t-shirts and YouTube video, ${ }^{5}$ were instrumental in fueling legitimacy and excitement for this project and for service-learning in general.

Changes and Improvements to the Service-learning Project

\section{More prescriptive design and force analysis guidance}

During the first ramp design-build, students spent too much time working out details on the design rather than focusing on the force analysis. The majority of time was spent trying to figure out how to build the ramp when much of that work was already available. It was not realistic to have them design from scratch, as most students in a second year engineering course do not have construction experience or training and they became distressed and overwhelmed at the prospect. Consequently, students participating in the first year project really did not fully meet the learning objectives of applying the statics/dynamics concepts to the project. 
In subsequent years, a "modular" design was used which greatly reduced the amount of time students spent on ramp building details and instead concentrated on the general layout and force analysis. Figure 1 shows an example of the "modular" nature of these wheelchair ramp designs. Each rectangle is the size of a $4 \times 8$ sheet of plywood or a ratio of the plywood section. The sections are then arranged according to the layout and topography of the building site.

Improvements to the implementation of the project were accomplished two ways: first, a smallscale model was used to show how the ramps are "modularized" and that several of these standard modules can be connected and configured to complete the ramp; second, another tour of previously built ramps was added a few weeks prior to the build date. Students had the chance to inspect several ramps to see how they were constructed and think about how the building of their ramp might be sequenced. The last stop on the tour is the location of the actual build site. Here students meet the ramp recipient(s), take measurements and pictures of the site, and start to develop their designs.

Secondly, clearer requirements for design loading, specifically, determining load limits and ensuring long spans will not exceed the modulus of rupture (a material's ability to resist deformation under load), were specified. More guidance for developing the force analysis eventually leading to the load limits and relating the modulus of rupture concept was included to better direct student efforts. Although modulus of rupture is touched on in statics, it is a central theme in engineering mechanics classes helping students to scaffold concepts between statics and mechanics of materials. To reinforce the connection between learning concepts and the ramp project, elements of the ramp are used in classroom problems. For example, when covering moments (the torque on an object), one example problem is a simplified model of a ramp support 
pole in concrete. Further class discussion about how that number relates to the building code and how the building code is developed make the connections between school and "real life."

\section{Building the ramp}

During the first ramp build student frustration was evident. There was no leader and students did not know what to do. Consequently, there was a lot of standing around which made students uncomfortable and feeling like they were not really participating. Some were embarrassed because they didn't know how to use some of the tools. The experience, for them, became more negative rather than a positive, empowering one.

To increase student comfort and facilitate an overall positive experience, students are now coached prior to the build. Both the instructor and agency ramp coordinator outline a typical build day, explain about "down time" especially when there are a lot of people working at the site, tips for sequencing job tasks, and job site etiquette. Ramp sketches from previous builds are shared, and the ramp coordinator explains how they were built. In class and on ramp tours students learn about each other's specialized skills and share ideas for teaching each other on the job site. They make preliminary plans about how they will group themselves and how they will sequence job tasks.

Implementing these improvements has not completely decreased down time, but has eliminated the negative and embarrassing feelings expressed by students during the first build. Students quickly learn that they have to be flexible with their tasks, are interdependent on each other, and they are much better at asking each other for help. Rather than standing idle, they tend to look around for small things they can do like cleaning and organizing the job site, getting drinks, and passing tools to each other.

One very important aspect that was not obvious in the first year was really making the connection to community. During the first build, the ramp recipients were not around during the building of the ramp and none of the students knew anything about the ramp recipients. This was particularly noteworthy since not one student in the first build mentioned anything about helping people. Now we meet the ramp recipient(s) in person prior to building the ramp and discuss their specific needs. After the build is

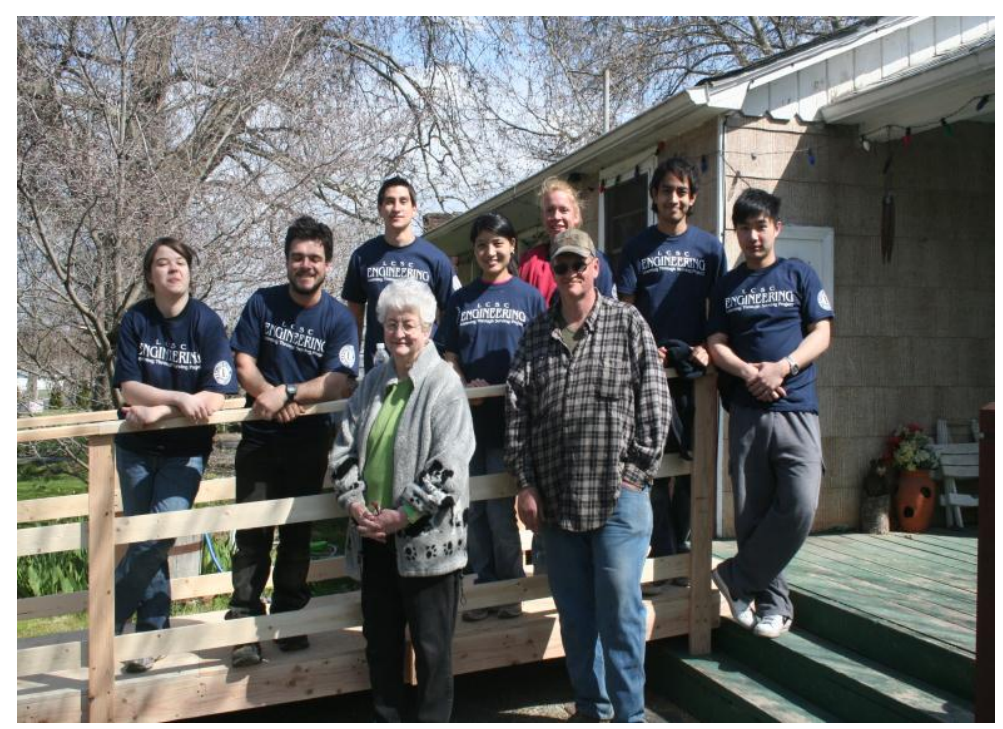

Figure 2. Finished ramp with students and recipients 
finished we take pictures with them. Student reflections since the change uniformly mention "helping people" and very often write about the recipients in detail. A picture from the $5^{\text {th }}$ year build project is shown in Figure 2.

\section{Ramp tour and dinner social}

The students tour approximately four ramps during the second ramp tour in the spring dynamics class and often have the opportunity to visit with the recipients. Looking at existing ramps that have already been completed helps students see what the ramps can look like, ways the ramp is incorporated with the residence, and how space constraints are handled. Since students in the spring dynamics class have already been through the design process the previous semester, they are much more cognizant of the needs and details for building the ramp. Now the spring ramp tour mirrors a "just-in-time" teaching strategy and has worked well with the short design/build timeframe. Students are already primed for the design project, and are prepared to critically evaluate existing ramps with respect to their designs. During the tour, they often ask the ramp owners how the ramp has worked for them. They use this input as they design the ramp they are about to build. As a final stop, the students visit the actual build site and talk with the recipient(s). This step has been crucial in connecting students to the community they are serving.

The tour ends at the instructor's house where everyone has a chance to visit and meet with other engineering students in a social setting. Students are encouraged to bring friends and significant others to dinner. An invitation is sent to all engineering students as this also serves as our "endof-year party." Other faculty are invited, and often physics and math professors who have many of the students in their classes, attend. This forum provides a wonderful opportunity for students and faculty to make connections with each other, and the addition of this social event with the second ramp tour appears to increase student camaraderie.

\section{Assessment}

A specific set of learning and service goals were developed for this project which are used for assessing and making improvements to the project. Students complete final reports at the end of the semester, after the build, which are used to demonstrate student learning and service goals.

Learning goals for this particular service-learning project are to: 1) demonstrate the ability to compute force analysis using concepts and techniques from statics and dynamics courses; 2) develop engineering judgment (developing, justifying, and documenting reasonable estimates, using acceptable resources like the USDA wood manual); and 3) make connections from concepts learned in class to "real life" by understanding how the Uniform Building Code and best practices in construction are developed. Service goals are to: 1) gain appreciation and evidence of how engineering fits into society, 2) be empowered to positively affect our community and assume leadership responsibilities; and 3) develop camaraderie among students, faculty/staff, and community members. 
A final report of the built ramp with the force analysis and project evaluation helps to assess the learning and service goals for this project. The report asks students for: 1) neat and clear sketches or drawings of the ramp showing analyzed force vectors; 2) structural (force) analysis for the different sections with written explanations; 3) cost estimates; 4) the maximum load for the ramp; 5) ideas for making the ramp build more efficient; 6) what surprised the student the most about the project and build; and, 7) how the student's work on the ramp affects the recipient(s). Questions one through five are used to assess their ability to relate what they are learning in the class to how that information is applied to the project, and questions six and seven are used to assess their experience and their perceptions of how they fit into the community.

\section{Results from learning goal improvements}

Although the actual questions and requirements for the report have changed slightly over the years, responses regarding the academic connection question from the first year were generally negative regarding relating class concepts to the ramp design project. In the first year many students responded that they had spent an inordinate amount of time with little return-essentially they felt the design was busy-work, and the build was nice but not really worth it. Reports from the last several years were overwhelmingly positive; students liked the design challenge and enjoyed getting to "do real engineering" and see their designs completed. Including "what to expect" in discussions about the construction, helping to sequence tasks, and knowing there will be times when students will be standing around has been key as it is rarely mentioned in reflections now.

\section{Results from service goal improvements}

Empowering students and engaging in a civic responsibility is a key part of the College's mission and a goal of this project. Questions six and seven of the assessment report are used to assess this. Based on responses from the first year of the project, several of the students wrote that this was a nice idea but not worth the time and effort. Since students started meeting the ramp recipients prior to the build, responses overwhelmingly described how they really appreciated helping the receiving family and indicated interest in helping with other service projects.

\section{Conclusion}

Research in service-learning suggests students benefit in several ways: greater ability to work more cooperatively in teams; advanced leadership and communication skills; more concrete understanding of basic engineering design principles; ability to be innovative and resourceful when confronted with problems, challenges, and conflicting information; increased self-efficacy and confidence; a new passion and motivation for engineering as a career choice; ${ }^{6,7}$ Along with gaining similar benefits, instructors also develop critical positive student-faculty interactions. ${ }^{8}$ Research indicates college students typically experience gains in learning and leadership development $^{6}$ as well as an increase in self-esteem when they engage in volunteer experiences. ${ }^{9}$ 
Additionally, service-learning increases students' metacognition and ability to be more innovative and resourceful with open-ended problems. ${ }^{10}$ Service-learning is especially valuable to engineering programs as it has been found to increase retention and increase participation by women and minorities. ${ }^{11}$

The engineering service-learning project has increased the pre-engineering's visibility and is recognized in the community by community partners. The program has grown an average of $20 \%$ per year and female and minority students have increased $30 \%$. The college president recently listed the project in his report to the State Legislature, and the Service-learning Center produced a video ${ }^{5}$ posted on YouTube about this project. There is a student-initiated engineering club Facebook page and a former student still uses his group photo of a finished ramp for his Facebook profile picture.

Shortly after the annual ramp project started, engineering students started taking on leadership positions in the College, engaging more in campus activities, and have started an engineering club. Prior to that no engineering students participated in student government and few participated in campus activities. This is particularly striking considering the program is a preengineering program and students have to transfer to another institution to complete their degrees (generally after their second year); yet they still develop strong ties to the College and their colleagues in that relatively short amount of time. Although follow-up has been limited, some of the students who first completed the wheelchair ramp project and have since graduated are now involved with our local Habitat for Humanity group-perhaps because of this project.

Research in service-learning and experiences with this project point to an increase in content knowledge, an increase in the number of entering engineering students, an increase in retention, and an increase in female and minority students. The increase in engineering students at our college, the higher-than-average retention rates, and an increase in college engagement since this service-learning project has been implemented certainly appear to support these conclusions.

\section{References}

${ }^{1}$ National Service Learning Clearinghouse, http://www.servicelearning.org/instant_info/fact_sheets/he facts/eng_ed; retrieved $1 / 25 / 12$.

${ }^{2}$ Tsang, E.; Projects That Matter: Concepts and Models for Service-Learning in Engineering, AAHE's Series on Service-Learning in the Disciplines, 2000. 
${ }^{3}$ Forest Products Laboratory. Wood handbook - Wood as an engineering material. General Technical Report FPLGTR-190. Madison, WI: U.S. Department of Agriculture, Forest Service, Forest Products Laboratory: 508 p. Retrieved 12/15/11;

http://www.fpl.fs.fed.us/products/publications/several_pubs.php?grouping_id=100\&header_id=p

${ }^{4}$ Uniform Building Code, 1997, International Conference of Building Officials - International Conference of Building Officials.

${ }^{5} 5^{\text {th }}$ Year Wheelchair Ramp, Dir. Lindsey Davies, 2011, Service Learning Center, Lewis-Clark State College, (youtube video) http://www.youtube.com/watch?v=vCa rnNWGHE

${ }^{6}$ Astin, A. W., and L. J. Sax. (1988). "How Undergraduates Are Affected by Service Participation." Journal of College Student Development 39(3): 251-263

${ }^{7}$ Eyler, J., \& Giles, D. E. (1999). Where's the learning in service-learning? San Francisco, CA: Jossey-Bass

${ }^{8}$ Bates, A.J., Drits, D., Allen, C., McCandless, P., Service Learning as an Instructional Strategy for the Preparation of Teachers, The Journal of Effective Teaching, Vol. 9, No. 1, 2009, 5-23;Retrieved 12/15/11. http://uncw.edu/cte/et/articles/Vol9_1/Bates.pdf

${ }^{9}$ Zlotkowski, E. (2002) (ed.) "Service-Learning and the First-Year Experience: Preparing Students for Personal Success and Civic Engagement" National Resource Center for the First-Year Experience \& Students in Transition. Monograph \#34

${ }^{10}$ Lemons, G., Carberry A., Swan, C., Jarvin, L.; The Effects of Service-Based Learning on Meta-Cognitive Strategies During an Engineering Design Task, International Journal for Service Learning in Engineering, Vol. 6, No. 2, pp. 1-18, Fall 2011, Retrieved 12/15/11. http://library.queensu.ca/ojs/index.php/ijsle/article/view/3561/4095

${ }^{11}$ A Preliminary Overview of the Literature Linking Service-Learning and Retention, Campus Compact National Office, January, 2006, retrieved 12/15/11. http://www.compact.org/wp-

content/uploads/resources/downloads/Retention_Literature_Review.pdf 